\title{
Axial Gout: Cinderella of Gouty Arthropathy!
}
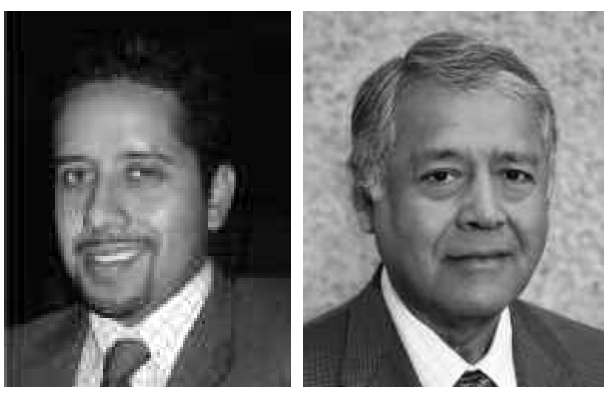

Gout and hyperuricemia are among the most important and common inflammatory-metabolic disorders, with treatment implications beyond the care of inflamed joints. Gout affects $1 \%$ to $2 \%$ of the population, and recent findings from nationally representative samples of adults in the US general population suggest that the prevalence of both gout and hyperuricemia remains substantial and may have increased over the past 20 years ${ }^{1}$. Better recognition of risk factors has also contributed to this increased incidence and prevalence, including the presence of comorbid conditions such as hypertension, diabetes, cardiovascular disease, and metabolic syndrome ${ }^{2}$. In addition, its clinical spectrum continues to expand, with recent descriptions of unusual clinical forms such as bone fracture, panniculitis, and axial or spondylitic involvement ${ }^{3,4}$.

Since 2009, when the last systematic review of axial gout cataloged 125 cases of gout ${ }^{5}$, there have been over 25 publications. Published cases mainly coalesce around the progression of inflammatory back pain to catastrophic neurological involvement ${ }^{6,7,8}$. Although these cautionary cases of axial involvement are likely rare, there is clearly interest and concern across specialties regarding the need for carefully constructed collective investigations to elucidate the contribution of axial gouty arthropathy.

In this issue of The Journal, Konatalapalli, et al provide an enticement to further investigate the prevalence and potential correlates of suspected axial gouty involvement ${ }^{9}$. Although limited by the cross-sectional design of their study, the findings precipitate key questions in regard to future investigative parameters.

In this study, the authors have provided important findings from a cross-section of gout patients with inclusion criteria being only poorly controlled gout - neither back pain nor neurological symptomatology was an identifying factor. This cohort is strikingly different from the collection of cases in the literature, of which the majority presented with manifestations mimicking emergent clinical presentations such as spinal tumors, spinal abscesses, spondylodiscitis, spinal stenosis, and spondyloarthropathy even responsive to nonsteroidal antiinflammatory drugs ${ }^{10}$. Although our only glimpse of the natural history of spinal gout has been gleaned from this unusual collection of published cases, what may be common to both groups is that urate-lowering therapy may shrink tophi deposited in spinal structures and relieve symptomatology $1,11,12$.

That both groups of gouty arthritis, those with and without axial involvement, were most likely under-treated, with a mean high serum uric acid and a striking predominance of no treatment or lack of appropriate treatment in this cross-sectional examination, highlights the need for contributions like those of the OMERACT Gout Working Group ${ }^{13}$ and of the American College of Rheumatology, with treatment guidelines currently under development. Lowering serum uric acid to $<6 \mathrm{mg} / \mathrm{dl}\left(<357 \mu \mathrm{mol} / 1^{14}\right)$ may also prevent progressive peripheral gouty arthropathy. However, it is uncertain whether this would have a beneficial effect on axial involvement. This raises questions about the natural history: further investigation is required regarding disease duration, treatment, and screening for axial involvement.

The correlation findings for back pain in this study defined as presence or absence of past or present history of back pain - did not differ between the axial and the non-axial group 9 . This is interesting and even surprising when compared to cumulative case series where lumbar involvement was predominantly associated with localized pain, with frequent radicular manifestations ${ }^{5}$. Although these 2 cohorts may not be comparable due to reporting bias, the presence of pain and radicular symptoms in future investigations still warrants close examination, with its assessment potentially being more complex and elusive than peripheral involvement, which may be accounted for by structural differences.

The study findings ${ }^{9}$ do not entirely answer the question about what is the best imaging modality to identify and fully characterize the radiological changes that develop secondary to urate crystal deposition. It appears, however, that

See Correlates of axial gout, page 1445

Personal non-commercial use only. The Journal of Rheumatology Copyright @ 2012 . All rights reserved. 
as with the appendicular skeleton, it takes several years of gout before radiological destructive changes or tophi become apparent in the axial skeleton. And although computed tomography imaging has been suggested as the best modality to detect these changes, the roles of various imaging techniques in the diagnosis of gout are being evaluated ${ }^{15,16}$.

In addition, the study suggests that diagnosis of axial gout may frequently be missed; however, the effects of missed diagnosis are unknown. Outside the devastating cases reported in published series, perhaps there is little effect on disability outcomes (the study was not able to assess disease duration or duration of poorly controlled disease). Or perhaps disease duration, examined in isolation, may distill differences in the impact of disease, as may the degree, location, and structures of spinal involvement?

Until investigations attempt to correlate the relationship between pain, functional measures, and/or health-related quality of life, these questions will remain unanswered. Without fully understanding the impact of axial gout, we cannot know the value of screening.

Although the cohort population is predominantly black, a significant difference was established between study populations, with blacks being subject to axial disease with more severe gouty involvement. This concurs with other study findings that have shown that blacks are twice as likely as whites to develop gout, experience more severe disease, and are less likely to be treated with urate-lowering therapy ${ }^{17,18}$.

This prompts another investigative question regarding genetic differences that could influence treatment strategies. Krishnan, et al recently performed a heritability analysis for hyperuricemia and gout among 514 unselected, all-male twin pairs who were a part of the National Heart, Lung, and Blood Institute twin study, a prospective observational cohort study ${ }^{19}$. The study population included 253 monozygotic and 261 dizygotic twin pairs, aged 48 years $( \pm 3)$ at baseline and followed for a mean of 34 years. The concordance of hyperuricemia was 53\% in monozygotic and 24\% in dizygotic twin pairs $(\mathrm{p}<0.001)$. The authors concluded that hyperuricemia is a genetic trait, but outside the context of rare genetic disorders, the environment determines risk for gout. This may have implications for prevention and treatment decisions.

Although limitations exist on several levels in their investigation $^{9}$, whatever the potential influence of gouty arthropathy, axial involvement may be common in chronic gout. The findings presented here hopefully have tipped the scales in favor of multicenter investigative attention. Perhaps the next best step is a carefully constructed registry with prospective data collection reporting patient symptoms, quality of life, functioning, medications with dosing, serology, radiologic items, cardiovascular variables, and very importantly, presence or absence of acute presentation ${ }^{20}$.

The glass slipper fits: axial gouty arthropathy exists and not uncommonly; it is now relevant to consider strategies on how to reveal its natural history and its response to treatment.

\author{
LESLEY A. SAKETKOO, MD, MPH, \\ Assistant Professor of Medicine, \\ Director, LSU Scleroderma and Sarcoidosis \\ Patient Care and Research Center; \\ IGNACIO GARCIA-VALLADARES, MD, \\ Senior Rheumatology Fellow; \\ LUIS R. ESPINOZA, MD, \\ Professor and Chief, \\ Section of Rheumatology, \\ Department of Medicine, \\ Louisiana State University Health Sciences Center, \\ New Orleans, Lousiana, USA
}

Address correspondence to Dr. L. Espinoza, Department of Medicine, LSU Health Sciences Center, 1542 Tulane Avenue, New Orleans, LA 70112-2822, USA. E-mail: lespin1@1suhsc.edu

\section{REFERENCES}

1. Zhu Y, Pandya BJ, Choi HK. Prevalence of gout and hyperuricemia in the US general population: The National Health and Nutrition Examination Survey 2007-2008. Arthritis Rheum 2011;63:3136-41.

2. Lottmann K, Chen X, Schadlich PK. Association between gout and all-cause as well as cardiovascular mortality: A systematic review. Curr Rheumatol Rep 2012;14:195-203.

3. Ochoa CD, Valderrama V, Mejia J, Rondon F, Villaroya N, Restrepo JF, et al. Panniculitis: Another clinical expression of gout. Rheumatol Int 2011;31:831-5.

4. Ning TC, Keenan RT. Unusual clinical presentations of gout. Curr Opin Rheumatol 2010;22:181-7.

5. Saketkoo LA, Robertson HJ, Dyer HR, Virk ZU, Ferreyro HR, Espinoza LR. Axial gouty arthropathy. Am J Med Sci 2009;338:140-6.

6. Nguyen C, Ea HK, Palazzo E, Liote F. Tophaceous gout: An unusual cause of multiple fractures. Scand J Rheumatol 2010;39:93-6.

7. Levin E, Hurth K, Joshi R, Brasington R. Acute presentation of tophaceous myelopathy. J Rheumatol 2011;38:1525-6.

8. Ibrahim GM, Ebinu JO, Rubin LA, de Tilly LN, Spears J. Gouty arthropathy of the axial skeleton causing cord compression and myelopathy. Can J Neurol Sci 2011;38:918-20.

9. Konatalapalli RM, Lumezanu E, Jelinek JS, Murphy MD, Wang H, Weinstein A. Correlates of axial gout: A cross-sectional study. J Rheumatol 2012;39:1445-9.

10. Justiniano M, Colmegna I, Cuchacovich R, Espinoza LR. Spondyloarthritis as a presentation of gouty arthritis. J Rheumatol 2007;34:1157-8.

11. Buenzli D, So A. Inflammatory sciatica due to spinal tophaceous gout. BMJ Case Rep 2009;2009. pii: bcr07.2008.0492.

12. Schorn C, Bahr C, Schwarting A. Fever and back pain - A case report of spinal gout. Dtsch Med Wochenschr 2010;135:125-8.

13. Gaffo AL, Schumacher HR, Saag KG, Taylor WJ, Dinnella J, Outman R, et al. Developing a provisional definition of flare in patients with established gout. Arthritis Rheum 2012;64:1508-17.

14. Zhang W, Doherty M, Bardin T, Pascual E, Barskova V, Conaghan $P$, et al. EULAR evidence based recommendations for gout. Part II: Management. Report of a task force of the EULAR Standing Committee for International Clinical Studies including Therapeutics (ESCISIT). Ann Rheum Dis 2006;65:1312-24.

15. Lumezanu E, Konatalapalli RM, Weinstein A. Axial (spinal) gout. Curr Rheumatol Rep 2012;14:161-4. Personal non-commercial use only. The Journal of Rheumatology Copyright @ 2012. All rights reserved. 
16. Dalbeth N, Doyle A, McQueen FM. Imaging in gout: Insights into the pathological features of disease. Curr Opin Rheumatol 2012;24:132-8.

17. Wells AF, Macdonald PA, Chefo S, Jackson RL. African American patients with gout: Efficacy and safety of febuxostat vs allopurinol. BMC Musculoskelet Disord 2012;13:15.

18. Singh JA. Can racial disparities in optimal gout treatment be reduced? Evidence from a randomized trial. BMC Med 2012;10:15.
19. Krishnan E, Lessov-Schlaggar CN, Krasnow RE, Swan GE. Nature versus nurture in gout: A twin study. Am J Med 2012;125:499-504.

20. Singh JA, Taylor WJ, Simon LS, Khanna PP, Stamp LK, McQueen FM, et al. Patient-reported outcomes in chronic gout: A report from OMERACT 10. J Rheumatol 2011;38:1452-7.

J Rheumatol 2012;39:1314-6; doi:10.3899/jrheum.120375 